University of Massachusetts Amherst

ScholarWorks@UMass Amherst

\title{
Determination of selenium by atomic absorption spectrometry with simultaneous retention of selenium(IV) and tetrahydroborate(III) on an anion-exchange resin followed by flow injection hydride generation from the solid phase
}

PE Carrero

JF Tyson

Follow this and additional works at: https://scholarworks.umass.edu/chem_faculty_pubs

Part of the Chemistry Commons

\section{Recommended Citation}

Carrero, PE and Tyson, JF, "Determination of selenium by atomic absorption spectrometry with simultaneous retention of selenium(IV) and tetrahydroborate(III) on an anion-exchange resin followed by flow injection hydride generation from the solid phase" (1997). ANALYST. 1072.

Retrieved from https://scholarworks.umass.edu/chem_faculty_pubs/1072 


\section{Determination of Selenium by Atomic Absorption Spectrometry With Simultaneous Retention of Selenium(IV) and Tetrahydroborate(III) on an Anion-exchange Resin Followed by Flow Injection Hydride Generation From the Solid Phase}

Pablo E. Carrero ${ }^{\dagger}$ and Julian F. Tyson*

Department of Chemistry, Box 34510, University of Massachusetts, Amherst, MA 01003-4510, USA

\begin{abstract}
Selenium(Iv) and tetrahydroborate(III) (borohydride) were simultaneously retained on a strong anion-exchange resin in a packed column. Hydrogen selenide was generated by passage of an injected zone of hydrochloric acid with subsequent detection by AAS with quartz tube atomization. The limits of detection, defined as the concentration giving a signal equal to $3 \mathrm{~s}$ of the blank, were $0.24,0.15$ and $0.12 \mu \mathrm{g} \mathrm{I}^{-1}$ of Se for 1,2 and $3 \mathrm{~min}$ preconcentration at a sample flow rate of $3 \mathrm{ml} \mathrm{min}^{-1}$, respectively. The precision of the procedure, expressed as the RSD of 10 successive determinations of 5, 10, and 20 $\mu \mathrm{g}^{-1}$ of Se, varied from 0.41 to $1.32,0.24$ to 0.81 and 0.18 to $0.61 \%$ for 1,2 and $3 \mathrm{~min}$ preconcentration, respectively. The system was used for the determination of selenium in river, lake and tap water matrices. No appreciable matrix effects were observed and the system was calibrated with aqueous solutions of a pure selenium salt $\left(\mathrm{Na}_{2} \mathrm{SeO}_{3}\right)$. The recoveries of spikes $(0.5,2$, and $10 \mathrm{\mu g} \mathrm{I}^{-1}$ of Se) added to the water samples ranged from 96.0 to $102.0,96.0$ to 107.0 and 98.9 to $108 \%$ for river, lake and tap water, respectively.
\end{abstract}

Keywords: Selenium(IV); ion-exchange preconcentration; solid-phase hydride generation; water analysis; flow injection

There are significant advantages in the use of hydride generation (HG) with AAS or other atomic spectrometric detection methods for the determination of elements which form volatile hydrides. Hydride generation has become one of the most powerful and well established techniques for the determination of arsenic, antimony, bismuth, germanium, lead, selenium, tellurium, tin, indium, and thallium. A variety of reactions have been used to convert the analyte in solution into the hydride. ${ }^{1-8}$ There are also several reports of electrochemical hydride generation ${ }^{9-11}$ and of thermochemical gas-phase hydride generation. ${ }^{12}$ In the case of solution reactions, a metalacid combination, or more commonly reaction with borohydride is employed for hydride generation. In early applications of the technique, the March reaction, based on a metal-acid system such as $\mathrm{Zn}-\mathrm{HCl}$ producing nascent hydrogen which reacted with the analyte to form the hydride, was used. ${ }^{3}$ The more commonly used reaction for hydride formation is the $\mathrm{BH}_{4}{ }^{-}$-acid reaction. ${ }^{13}$

Although some precursors are hydrated cations in the appropriate oxidation state, as for example with $\mathrm{Pb}^{\mathrm{Iv}}$; for most analytes the precursor may well exist as an oxo-anion which is reduced prior to the final hydride transfer reaction, as would be

† On leave from IVAIQUIM (Venezuelan Andean Institute for Chemical Research), Faculty of Sciences, University of Los Andes, P.O. Box 542, Mérida 5101-A, Venezuela. the case with $\mathrm{Se}^{\mathrm{IV}}$. Initial applications used $\mathrm{NaBH}_{4}$ pellets, but an aqueous solution stabilized by potassium or sodium hydroxide ${ }^{4}$ may be conveniently used and is currently the most popular reagent. Other forms of borohydride have been used. Borohydride bound to a stationary phase in a column has been used for hydride generation of arsenic 5,6 and selenium. 7,8 However, the only advantage reported over the use of an aqueous solution of $\mathrm{BH}_{4}$ - was the suppression of some matrix interferences.

In our current work on hydride generation with in-atomizer trapping for determination of low concentrations of selenium by ETAAS, ${ }^{14}$ we have found that detection limits are governed by impurities in the borohydride reagent. We considered that the immobilization of borohydride on an anion-exchange resin might result in a purer reagent and hence improved detection limits.

In the course of this study, we found that selenium was retained on the anion-exchange resin and that hydrogen selenide could be generated from the resin by the passage of acid when both selenium and borohydride were co-immobilized. In this paper, we report on the analytical performance of a system for the determination of selenium based on this method of generation of hydrogen selenide.

\section{Experimental}

Reagents

All reagents were obtained from Fisher (Pittsburgh, PA, USA) and were of analytical-reagent grade, unless stated otherwise. Doubly distilled $18 \mathrm{M} \Omega$ E-pure water was used throughout the experiment. A stock standard solution of $1000 \mathrm{mg} \mathrm{l}^{-1}$ of selenite $\left(\mathrm{SeO}_{3}{ }^{2-}\right)$ was used. Other concentrations were obtained by dilution. Sodium borohydride, $10 \% \mathrm{~m} / \mathrm{v}$ in $2 \% \mathrm{~m} / \mathrm{v}$ sodium hydroxide, was filtered through Whatman No. 2 filter-paper and stored at $4{ }^{\circ} \mathrm{C}$ for 4 weeks without deterioration. Other concentrations were obtained by dilution. The resins used were Amberlite IRA-410 and Amberlyst A26 (Aldrich, Milwaukee, WI, USA), which are strongly basic anion-exchange resins (styrene-divinylbenzene skeletal structure).

\section{Apparatus}

The detection unit used was a Perkin-Elmer (Norwalk, CT, USA) Model 3100 atomic absorption spectrometer. The atomizer was a flame-heated quartz T-shaped tube. The quartz tube was cleaned weekly with acid following the procedure described by Hatfield. ${ }^{15}$ A hollow-cathode lamp (Perkin-Elmer) was used as a light source. The wavelength for Se was $196.0 \mathrm{~nm}$. The spectral bandpass was $0.7 \mathrm{~nm}$. 


\section{Manifold}

The manifold, shown schematically in Fig. 1, was constructed from $0.8 \mathrm{~mm}$ id PTFE tubing, except the tubing between the argon confluence point, the gas-liquid separator and quartz tube, which was PTFE tubing of $1.5 \mathrm{~mm}$ id. The gas-liquid separator consisted of a $25 \mathrm{ml}$ separating funnel with a twoholed rubber cap. The column consisted of a glass tube of 150 $\mathrm{mm}$ length and $4 \mathrm{~mm}$ id. Two PTFE reducing unions of $1 / 4 \times$ $1 / 8$ in (Cole-Parmer, Chicago, IL, USA), fitted at either end of the column, were used to connect it to the manifold.

A slurry of anion-exchange resin was introduced into the column with the aid of a syringe. A small amount of glass-wool was placed at the ends of the column to prevent loss of the resin. The column was ready for use after washing several times alternately with borohydride and hydrochloric acid solutions. Two six-port PTFE Rheodyne rotary valves (Supelco, Bellefonte, PA, USA) were used. The ion-exchange column was located in the injection loop of one and the other was used to introduce a discrete volume $(500 \mu 1)$ of acid. Two Ismatec SA MS-Reglo Model 7331-10 peristaltic pumps (from ColePalmer) were used, one for the carrier line and the other for the acid, sample, and borohydride lines. The waste from the gasliquid separator was pumped with a Lachat Instruments (Milwaukee, WI, USA) Model 1200-000 peristaltic pump. The flows of reagents were regulated by using Tygon pump tubing (Cole-Parmer) of different internal diameters and by control of the pump head rotation speed.

\section{Recommended Procedure}

All the experiments were carried out using the manifold shown in Fig. 1. In the load position, Fig. 1(a), the sample of selenite $\left(\mathrm{SeO}_{3}{ }^{2-}\right)$ and the borohydride were mixed and pumped through the column for a period of 1,2 or $3 \mathrm{~min}$, resulting in the simultaneous retention of both anions $\left(\mathrm{SeO}_{3}{ }^{2-}\right.$, or possibly $\mathrm{Se}^{2-}$, and $\mathrm{BH}_{4}^{-}$). At the same time, the loop of valve 1 was filled with acid, while the de-ionized water carrier was pumped constantly through the system. In the injection position, Fig. 1(b), valve 2 was switched and the column was washed for a period of $20 \mathrm{~s}$ with carrier solution. Valve 1 was then switched and the acid was carried through the column generating

(a)

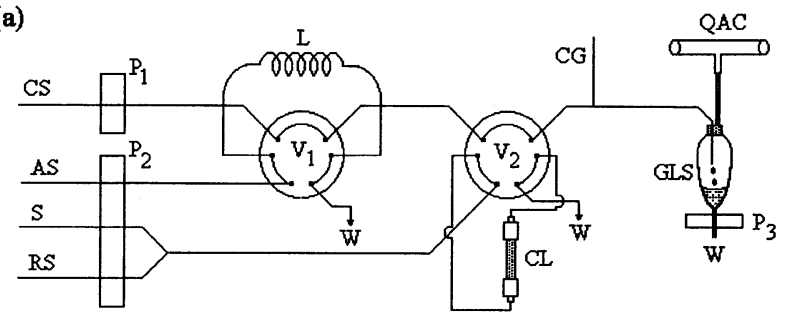

(b)

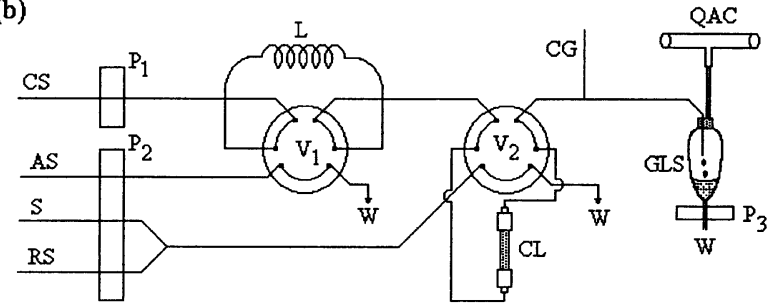

Fig. 1 Schematic diagram of the manifold for selenium preconcentration and hydride generation. (a) load position and (b) injection position. $\mathrm{V}_{1,2}$, six-port valves; $\mathrm{P}_{1,2,3}$, peristaltic pumps; $\mathrm{QAC}$, quartz atomization cell; GLS, gas-liquid separator; CL, column packing with strong anionexchange resin; L, $500 \mu$ l loop; CS, carrier solution, distilled, deionized 18 $\mathrm{M} \Omega$ E-pure water $\left(14 \mathrm{ml} \mathrm{min}^{-1}\right) ; \mathrm{AS}, 4 \mathrm{~mol} \mathrm{l}^{-1} \mathrm{HCl}(1.5 \mathrm{ml} \mathrm{min}-1)$; RS, $0.05 \% \mathrm{~m} / \mathrm{v} \mathrm{NaBH}$ in $0.01 \% \mathrm{~m} / \mathrm{v} \mathrm{NaOH}(3.0 \mathrm{ml} \mathrm{min}-1)$; $\mathrm{S}$, sample (3.0

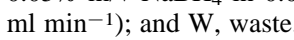

hydrogen selenide. The column was cleaned between samples and standards by passing $4 \% \mathrm{~m} / \mathrm{v}$ borohydride in $0.5 \% \mathrm{~m} / \mathrm{v}$ $\mathrm{NaOH}$ for $30 \mathrm{~s}$ followed by an injection of acid. The cleaning step was not needed between replicate injections of the same sample or standard.

\section{Method Development}

\section{Determination of arsenic}

Initial experiments involved repeating the procedures described by Tesfalidet and Irgum $^{5}$ and Narasaki et al. ${ }^{6}$ for the determination of arsenic. In these procedures, the borohydride was first loaded on to the anion-exchange column and, after washing, the acidified analyte solution was passed through the column generating arsine and hydrogen. These experiments are not described in detail here. The detailed experimental work concerns the development of the new procedure for the determination of selenium.

\section{Gas-liquid separation}

Two types of gas-liquid separator were used, namely the Perkin-Elmer device from the FIAS unit (this was the empty plastic vessel) and a device constructed in-house from a $25 \mathrm{ml}$ separating funnel. In neither case was any additional device used to reduce the transfer of water vapor or droplets to the atomizer. The drains from both these devices were pumped. In the case of the separating funnel device the drain pump rate was such that there was always $1-2 \mathrm{ml}$ of liquid in the funnel.

\section{Column dimensions}

Two different strongly basic resins, Amberlite IRA-410 and Amberlyst A26, were packed in columns of various dimensions. Four different lengths $(50,100,150$ and $200 \mathrm{~cm})$ and two different internal diameters (2 and $4 \mathrm{~mm}$ ) were used in all possible combinations. Both resins have styrene-divinylbenzene skeletal structures; however, Amberlite IRA-410 is a gel-type resin and Amberlyst A26 is a porous or macroreticular resin. The resulting columns were tested for selenium retention and subsequent hydride generation for six replicate measurements at two concentrations of selenium, 10 and $25 \mu \mathrm{g} \mathrm{l}^{-1}$.

\section{Parameter optimization}

The multi-cycle alternating variable search optimization method $^{16,17}$ was used for the optimization of the following parameters: borohydride concentration, $\mathrm{HCl}$ concentration, carrier flow rate and stripping gas flow rate. The figure of merit for the optimization process was maximum net peak height sensitivity (i.e., signal minus blank). Other parameters that were studied include the dimensions of the column, nature of the anion-exchange resin, oxidation state of the selenium and the flow rates of the sample and borohydride solutions.

Parameter optimization was carried out with a $1 \mathrm{~min}$ preconcentration (at $3 \mathrm{ml} \mathrm{min}-1$ sample and borohydride flow rates), using a column size of $150 \times 4 \mathrm{~mm}$ id packed with Amberlite IRA-410 anion-exchange resin. The optimization of the borohydride and $\mathrm{HCl}$ concentrations was carried out using sample solutions of 0,10 and $25 \mu \mathrm{g}^{-1}$ of Se. The effect of such reagents was studied by varying these concentrations within the ranges $0.01-2 \% \mathrm{~m} / \mathrm{v} \mathrm{NaBH} 4$ in $0.01 \% \mathrm{~m} / \mathrm{v} \mathrm{NaOH}$, and $0.1-2$ mol $1^{-1} \mathrm{HCl}$. Samples of 10 and $25 \mu \mathrm{g} \mathrm{l}^{-1}$ were used in the studies of the effects of the argon stripping gas flow rate and the carrier flow rate, i.e., the speed at which the acid passed through the column. The argon flow rates were varied between 50 and 
$1000 \mathrm{ml} \mathrm{min}^{-1}$. The carrier flow rate was varied between 4 and $15 \mathrm{ml} \mathrm{min}^{-1}$.

\section{Analytical Performance}

Using the optimal experimental conditions (given in Table 1), calibration graphs with $0,5,10,15,20$, and $25 \mu \mathrm{g}{ }^{-1}$ of Se for 1,2 and 3 min of preconcentration were made. The precision of the system was evaluated as the RSD of 10 successive determinations of 5,10 and $20 \mu \mathrm{g} \mathrm{l}^{-1}$ of Se for 1, 2 and $3 \mathrm{~min}$ of preconcentration, respectively. The accuracy was evaluated by means of the recovery of $0.5,2$ and $10 \mu \mathrm{g}^{-1}$ of Se spiked in river, lake and tap water.

The effect of the sample matrix was evaluated by the method of standard additions. Equal volumes of river, lake and tap water $(45 \mathrm{ml})$ were taken, all but one were separately spiked with different amounts of selenium and then all were diluted to equal volumes $(50 \mathrm{ml})$ to obtain three series of solutions with final concentrations added of $0,5,10,15,20$ and $25 \mu \mathrm{g} 1^{-1}$ of Se. Signals were obtained under the optimal experimental conditions (Table 1) for a $3 \mathrm{~min}$ preconcentration time. All calibrations were obtained by an unweighted least-squares procedure.

\section{Results and Discussion}

\section{Determination of Arsenic}

The results reported previously5,6 for the determination of arsenic were confirmed. Signals were obtained for both $\mathrm{As}^{\mathrm{III}}$ and $\mathrm{As}^{\mathrm{V}}$. For a sample volume of $835 \mu \mathrm{l}$, the linear ranges for $\mathrm{As}^{\mathrm{III}}$ and $\mathrm{As}^{\mathrm{v}}$ were $0.6-40$ and $0.9-50 \mu \mathrm{g}^{-1}$, respectively. The precisions, expressed as RSD for five replicate determinations of $20 \mu \mathrm{g} \mathrm{l}^{-1}$, were between $1.8 \%$ and $3.2 \%$ for $\mathrm{As}^{\mathrm{III}}$ and between $2.4 \%$ and $4.1 \%$ for $\mathrm{As}^{\mathrm{v}}$.

\section{Gas-Liquid Separator}

The device based on the $25 \mathrm{ml}$ separating funnel was used, rather than the smaller internal volume Perkin-Elmer device, to avoid the carry-over of liquid which tends to occur with certain combinations of argon gas flow rate and borohydride concentration with devices having small internal volumes. As the optimization studies required that these parameters be varied, the use of a more robust gas-liquid separator decreased the down-time spent cleaning and regenerating the surface of the quartz cell. However, for an FI-based procedure the gas-liquid separator will affect the peak height sensitivity by virtue of a contribution to the overall dispersion and it is likely that the

Table 1 Optimum operation conditions

$\begin{array}{lc}\text { Atomic absorption spectrometer- } & \\ \text { Wavelength } & 196 \mathrm{~nm} \\ \text { Slit width } & 0.7 \mathrm{~nm} \\ \text { Lamp current } & 16 \mathrm{~mA} \\ \text { Quartz cell temperature } & 900{ }^{\circ} \mathrm{C} \\ \text { Background correction } & \mathrm{On}\end{array}$

On-line preconcentration and hydride generation-

$\begin{array}{lc}\mathrm{HCl} \text { concentration } & 4 \mathrm{~mol} \mathrm{l}^{-1} \\ \mathrm{NaBH}_{4} \text { concentration } & 0.05 \% \mathrm{~m} / \mathrm{v} \\ \mathrm{Sample}^{-1} \text { flow rate } & 3.0 \mathrm{ml} \mathrm{min}{ }^{-1} \\ \mathrm{NaBH}_{4} \text { flow rate } & 3.0 \mathrm{ml} \mathrm{min}^{-1} \\ \text { Carrier flow rate } & 14.0 \mathrm{ml} \mathrm{min}^{-1} \\ \text { Argon flow rate } & 100 \mathrm{ml} \mathrm{min}^{-1} \\ \text { Column size }(\text { length } \times \text { id) } & 150 \times 4 \mathrm{~mm} \\ \text { Resin } & \text { Amberlite IRA-410 }\end{array}$

device used here is sub-optimal with respect to this characteristic.

\section{Column Dimensions and Resin Type}

The best results were observed with larger column sizes (lengths and id) with both resins, i.e., when the amount of resin was increased. However, lengths above $150 \mathrm{~mm}$ for the same internal diameter did not produce any improvement in the signal. The Amberlite IRA-410 gel-type resin produced better results than the Amberlyst A26 macroreticular resin. Therefore, a $150 \times 4 \mathrm{~mm}$ id column packed with Amberlite IRA-410 geltype resin was chosen for further experiments.

\section{Parameter Optimization}

The optimum conditions are given in Table 1. No signals were obtained from solutions of $\mathrm{Se}^{\mathrm{VI}}$. To achieve the best sensitivity, three cycles of the optimization process were necessary. The results of the third cycle for each parameter are discussed below. The effect of the concentration of borohydride is shown in Fig. 2. There was a steady increase in the blank signal as the concentration of borohydride increased from 0.01 to $1.0 \% \mathrm{~m} / \mathrm{v}$, with a slower increase from 1.0 to $2.0 \% \mathrm{~m} / \mathrm{v}$. For both samples (10 and $25 \mu \mathrm{g}^{-1}$ of $\mathrm{Se}$ ) a sharp increase in the signal was observed as the borohydride concentration increased from 0.01 to $0.05 \% \mathrm{~m} / \mathrm{v} \mathrm{NaBH}$, followed by a sharp decrease from 0.5 to $1.0 \% \mathrm{~m} / \mathrm{v}$. No signal was obtained in the absence of borohydride. The $0.05 \% \mathrm{~m} / \mathrm{v}$ concentration produced the optimum net signal. This concentration of borohydride is considerably lower than that used in typical flow injection and typical batch procedures.

The effect of the concentration of $\mathrm{HCl}$ is shown in Fig. 3. As can be seen, the signals from the samples and the blank increased as the $\mathrm{HCl}$ concentration increased to $0.5 \mathrm{~mol}^{-1}$, but changed little thereafter. Therefore, $4 \mathrm{~mol} \mathrm{l}^{-1}$ was chosen for further experiments.

The effect of carrier flow rate is shown in Fig. 4. Carrier flow rates between 12 and $15 \mathrm{ml} \mathrm{min}^{-1}$ resulted in the best net absorbance signal. A carrier flow rate of $14 \mathrm{ml} \mathrm{min}^{-1}$ was used in further experiments. The effect of the stripping gas flow rate is shown in Fig. 5. The most favorable rate was found to be 180 $\mathrm{ml} \mathrm{min}-1$, hence this value was chosen for further experiments.

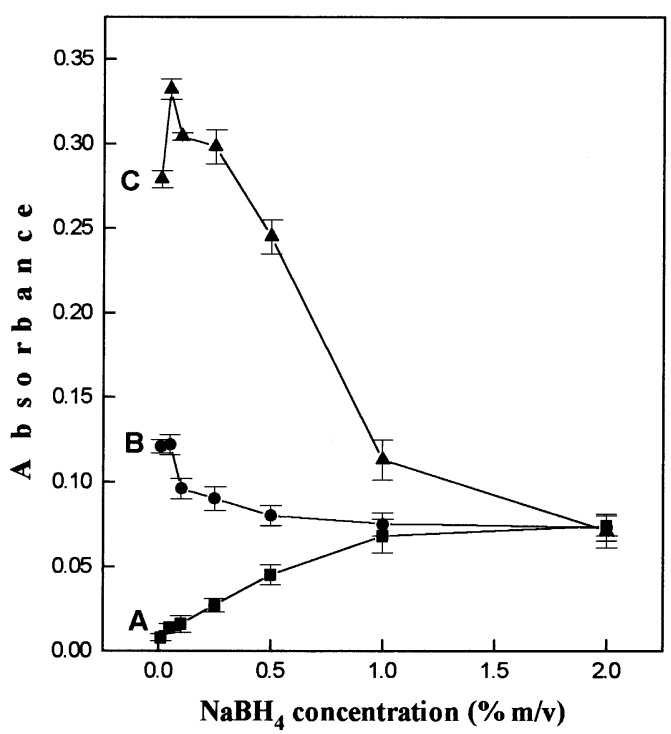

Fig. 2 Effect of concentration of $\mathrm{NaBH}_{4}$ solution on the signal peak height (absorbance). A, no Se; B, $10 \mu \mathrm{g} 1^{-1}$ of Se; and C, $25 \mu \mathrm{g} \mathrm{1^{-1 }}$ of Se. The error bars represent the standard deviation for five replicate measurements. 


\section{Analytical Performance}

The calibration equations and the other performance figures of merit are summarized in Table 2 . The system responded linearly from the detection limit up to 180,120 and $80 \mu \mathrm{g} 1^{-1}$ of Se for

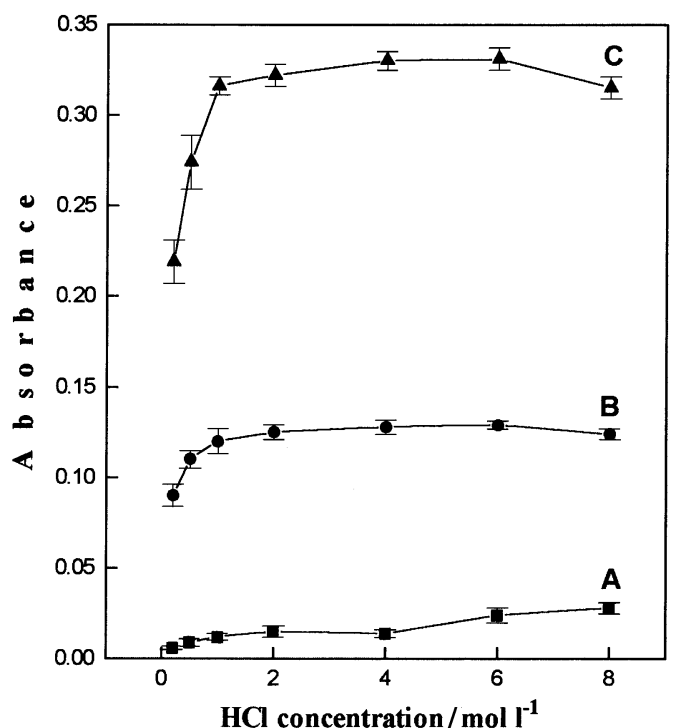

Fig. 3 Effect of concentration of $\mathrm{HCl}$ solution on the signal peak height (absorbance). A, no Se; B, $10 \mu \mathrm{g} \mathrm{l}^{-1}$ of Se; and C, $25 \mu \mathrm{g}^{-1}$ of Se. The error bars represent the standard deviation for five replicate measurements.

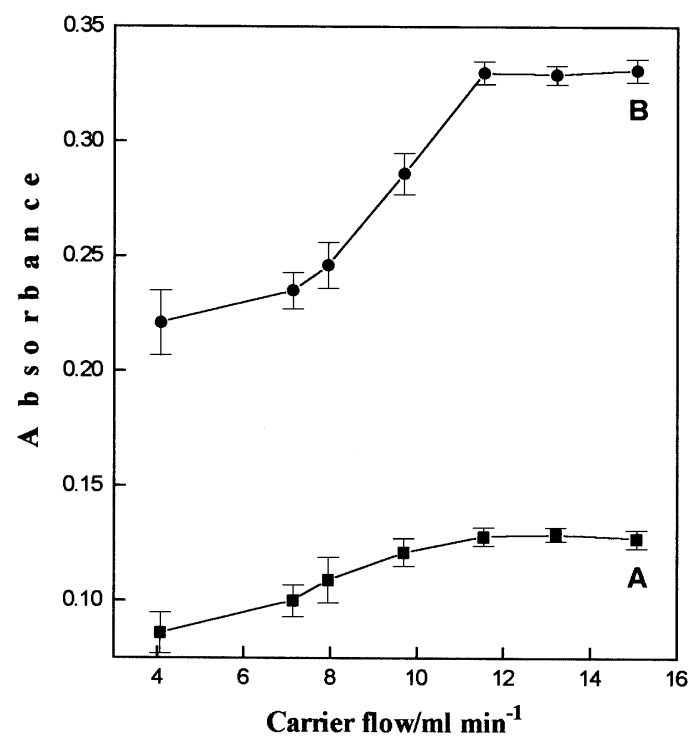

Fig. 4 Effect of the carrier solution flow on the net signal peak height (absorbance). A, $10 \mu \mathrm{g}^{-1}$ of Se; and B, $25 \mu \mathrm{g} \mathrm{1^{-1 }}$ of Se. The error bars represent the standard deviation for five replicate measurements.
1, 2 and 3 min preconcentration, respectively. The precision of the procedure as a function of concentration, expressed as RSD, varied from 0.41 to $1.32,0.24$ to 0.81 and 0.18 to $0.61 \%$ for 1 , 2 and 3 min preconcentration, respectively. The precision of the system improved with preconcentration time, but degraded severely if the residual sample and borohydride were not washed from the column. Carry-over between samples and standards was prevented by flushing residual selenium from the column with the $4 \%$ borohydride wash. The limits of detection, defined as the concentration giving a signal equal to three times the standard deviation of the blank signal, were $0.24,0.15$ and $0.12 \mu \mathrm{g} 1^{-1}$ of $\mathrm{Se}$ for 1,2 and $3 \mathrm{~min}$ preconcentration, respectively. The sample throughput was $21 \mathrm{~h}^{-1}$ for $1 \mathrm{~min}$ preconcentration.

The results of the standard additions to the water sample matrices were compared with those for the same concentrations in distilled water. The characteristics of the regression lines are summarized in Table 3 . The $95 \%$ confidence interval about the slope of the calibration in the distilled water matrix contains the slopes of the calibrations in the other matrices, i.e., the confidence intervals of the slopes overlap in all cases and there is no significant difference between the slopes for the different matrices. As no appreciable matrix effect was observed, the analyses of the test samples were performed by calibration with aqueous solutions of a pure selenium salt $\left(\mathrm{Na}_{2} \mathrm{SeO}_{3}\right)$.

The recoveries (and standard deviations) of spikes added to the water samples are given in Table 4 and ranged from $96 \pm 4$ to $102 \pm 6,96 \pm 4$ to $107 \pm 6$ and $99 \pm 4$ to $108 \pm 6 \%$, depending on the concentration, for river, lake and tap water, respectively. These values indicate that selenium can be quantitatively determined in such samples.

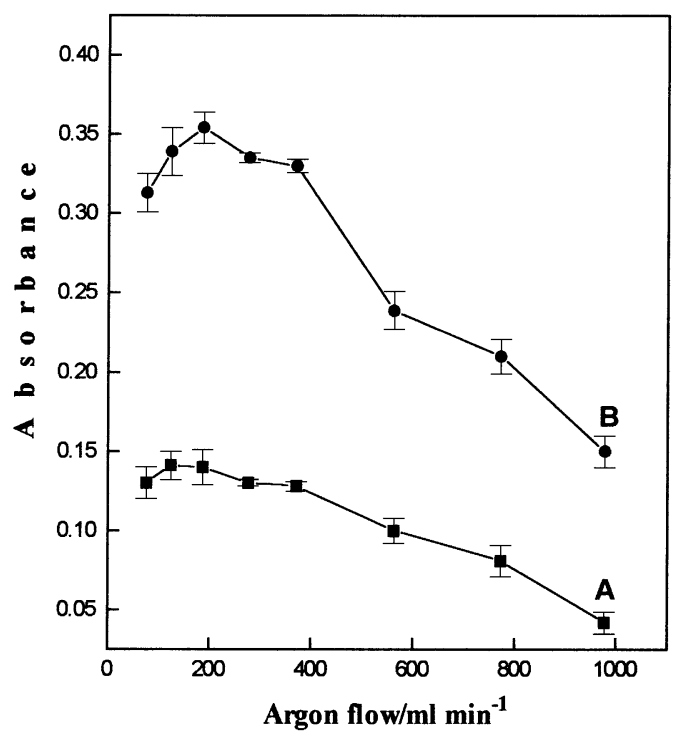

Fig. 5 Effect of stripping gas (argon) flow rate on the net signal peak height (absorbance). A, $10 \mu \mathrm{g} \mathrm{l}^{-1}$ of Se; and B, $25 \mu \mathrm{g} \mathrm{1^{-1 }}$ of Se. The error bars represent the standard deviation for five replicate measurements.

Table 2 Analytical performance of the system

\begin{tabular}{|c|c|c|c|c|c|c|}
\hline \multirow[b]{2}{*}{$\begin{array}{l}\text { Time*/ } \\
\text { (min) }\end{array}$} & \multirow{2}{*}{$\begin{array}{c}\text { Regression } \\
\text { equation: } \\
A=b+m C^{\dagger}\end{array}$} & \multirow[b]{2}{*}{$r^{*}$} & \multirow{2}{*}{$\begin{array}{c}\operatorname{LOD}(3 s)^{\S /} \\
\mu \mathrm{g} 1^{-1}\end{array}$} & \multicolumn{3}{|c|}{$\operatorname{RSD}(\%)^{\mathrm{q}}$} \\
\hline & & & & $5 \mu \mathrm{g}^{-1}$ & $10 \mu \mathrm{g} 1^{-1}$ & $20 \mu \mathrm{g} \mathrm{l}^{-1}$ \\
\hline 1 & $A=0.011+0.0123 C$ & 0.9996 & 0.24 & 1.32 & 0.83 & 0.41 \\
\hline 2 & $A=0.022+0.0197 C$ & 0.9997 & 0.15 & 0.81 & 0.46 & 0.24 \\
\hline 3 & $A=0.035+0.0256 C$ & 0.9997 & 0.12 & 0.61 & 0.36 & 0.18 \\
\hline
\end{tabular}

* Time of passage of sample through the column at $3 \mathrm{ml} \mathrm{min}{ }^{-1}$. ${ }^{\dagger} A$ is absorbance, $b$ is intercept, $m$ is slope and $C$ is concentration of Se in $\mu \mathrm{g}^{-1}$. $¥$ Regression coefficient. \$ LOD $(3 s)$ is the detection limit, calculated for $3 \mathrm{~s} / \mathrm{m}$, where $s$ is the within-run standard deviation of a blank determination $(n=10)$. II RSD for 5,10 and $20 \mu \mathrm{g} 1^{-1}$ of Se $(n=10)$. 


\section{Determination of $S^{I V}$ in Water}

The results of the application of the proposed method to the determination of selenium in river, lake and tap water are given

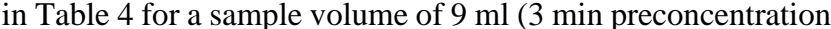
time). The concentration of selenium in the river water sample was $0.14 \pm 0.01 \mu \mathrm{g} 1^{-1}$. The concentrations of selenium in the lake and tap water samples analyzed were below the detection limit of $0.12 \mu \mathrm{g}^{-1}$. It is known that the concentration of $\mathrm{SeO}_{3}{ }^{2-}$ in natural water ${ }^{18-20}$ is usually very low and that selenium is present in water in various oxidation states and chemicals forms, including organic species. ${ }^{18,21,22}$

\section{Conclusions}

The co-immobilization of selenium and borohydride on an anion-exchange resin followed by passage of acid forms the

Table 3 Standard additions of selenium to water samples

Regression line characteristics

\begin{tabular}{lccccccc} 
& \multicolumn{7}{c}{ Regression line characteristics } \\
\cline { 2 - 8 } \multicolumn{1}{c}{ Matrix } & Slope & $s_{\text {slope }}$ & $\begin{array}{c}\text { Confi- } \\
\text { dence } \\
\text { limits* }\end{array}$ & Intercept & $s_{\text {int }}$ & $r^{\dagger}$ \\
Distilled water & 0.0257 & 0.00048 & 0.0013 & 0.032 & 0.0073 & 0.9995 \\
River water & 0.0249 & 0.00045 & 0.0012 & 0.039 & 0.0067 & 0.9998 \\
Lake water & 0.0251 & 0.00045 & 0.0012 & 0.035 & 0.0069 & 0.9998 \\
Tap water & 0.0248 & 0.00043 & 0.0012 & 0.034 & 0.0061 & 0.9999
\end{tabular}

* Confidence limits for the slope, given by $t$; the $t$-value was taken at the $95 \%$ confidence level and $n-2$ degrees of freedom. + Correlation coefficient.

Table 4 Analytical results for various water samples

\begin{tabular}{|c|c|c|c|}
\hline Sample & $\begin{array}{l}\text { Selenium } \\
\text { added/ } \\
\mu \mathrm{g} 1^{-1}\end{array}$ & $\begin{array}{l}\text { Selenium } \\
\text { found/ } \\
\mu \mathrm{g} 1^{-1}\end{array}$ & Recovery (\%) \\
\hline $\begin{array}{l}\text { River water } \\
\quad \text { (Fort river, Amherst) }\end{array}$ & $\begin{array}{r}0 \\
0.5 \\
2.0 \\
10.0\end{array}$ & $\begin{array}{r}0.14 \pm 0.01 \\
0.65 \pm 0.03 \\
2.06 \pm 0.07 \\
10.05 \pm 0.39\end{array}$ & $\begin{array}{r}-\overline{102 \pm 6} \\
96 \pm 4 \\
99 \pm 4\end{array}$ \\
\hline $\begin{array}{l}\text { Lake water } \\
\text { (Puffers Pond, } \\
\text { Sunderland) }\end{array}$ & $\begin{array}{r}0 \\
0.5 \\
2.0 \\
10.0\end{array}$ & $\begin{array}{c}<\mathrm{DL}^{*} \\
0.48 \pm 0.02 \\
2.05 \pm 0.05 \\
10.70 \pm 0.56\end{array}$ & $\begin{array}{r}- \\
96 \pm 4 \\
103 \pm 3 \\
107 \pm 6\end{array}$ \\
\hline $\begin{array}{l}\text { Tap water } \\
\text { (Amherst) }\end{array}$ & $\begin{array}{r}0 \\
0.5 \\
2.0 \\
10.0\end{array}$ & $\begin{array}{c}<\mathrm{DL}^{*} \\
0.54 \pm 0.03 \\
2.01 \pm 0.05 \\
9.89 \pm 0.43\end{array}$ & $\begin{array}{r}- \\
108 \pm 6 \\
101 \pm 3 \\
99 \pm 4\end{array}$ \\
\hline
\end{tabular}

basis of a viable method for the determination of selenium by HGAAS and quantitative recovery of selenium from water samples can be achieved. The procedure could be fully automated via a system of computer-controlled valves and pumps and can be used with any atomic spectrometric detection system. Work is in progress to implement the procedure on a Perkin-Elmer FIAS unit. The preconcentration of the analyte on the anion-exchange column allows the potential for improved sensitivity over conventional flow injection hydride generation techniques and the possibility of the separation of the analyte from cation interferences. Current development of the procedure is focused on overcoming such matrix interferences as it may be possible to immobilize the sample and the borohydride successively.

Financial support from the University of the Andes, Mérida, Venezuela, for P.C. is gratefully acknowledged and the authors thank Robert I. Ellis for helpful discussions.

\section{References}

1 Nakahara, T., Spectrochim. Acta Rev., 1991, 14, 95.

2 Godden, R. G., and Thomerson, D. R., Analyst, 1980, 105, 1137.

3 Branch, C. H., and Hutchison, D., Analyst, 1985, 110, 163.

4 Agterdenbos, J., and Bax, D., Fresenius' Z. Anal. Chem., 1986, 323, 783.

5 Tesfalidet, S., and Irgum, K., Anal. Chem., 1989, 61, 2079.

6 Narasaki, H., Kato, Y., and Kimura, H., Anal. Sci., 1992, 8, 893.

7 Cao, J.Y., and Narasaki, H., Bunseki Kagaku, 1994, 43,169.

8 Tesfalidet, S., and Irgum, K., Fresenius' J. Anal. Chem., 1991, 341, 532.

9 Brockmann, A., Nonn, C., and Golloch, A., J. Anal. At. Spectrom., 1993, 8, 397.

10 Lin, Y., Wang, X., Yuan, D., Yang, P., Huang, B., and Zhuang, Z., J. Anal. At. Spectrom., 1992, 7, 287.

11 Ding, W.-W., and Sturgeon, R. E., J. Anal. At. Spectrom., 1996, 11, 225.

12 Blais, J. S., Momplaisir, G. M., and Marshall, W. D., Anal. Chem., 1990, 62, 1161.

13 Howard, A. G., J. Anal. At. Spectrom., 1997, 12, 267.

14 Tyson, J. F., Sundin, N. G., Hanna, C. P., and McIntosh, S. A., Spectrochim. Acta Part B, in the press.

15 Hatfield, D. B., Anal. Chem., 1987, 59, 1887.

16 Greenfield, S., Salman, M. S., Thomsen, M., and Tyson, J. F., J. Anal. At. Spectrom., 1989, 4, 55.

17 Miller, J. C., and Miller, J. N., Statistics for Analytical Chemistry, 3rd edn, Ellis Horwood, Chichester, 1993, pp. 185-187.

18 Cutter, G. A., Anal. Chim. Acta, 1978, 98, 59.

19 Measures, C. I., and Burton, J. D., Nature (London), 1978, 273, 293.

20 Yu, Q., Liu, G. Q., and Jin, Q., Talanta, 1983, 30, 265.

21 Cutter, G. A., Anal. Chim. Acta, 1983, 149, 391.

22 Robberecht, H., and Van Grieken, R., Talanta, 1982, 29, 823.

Paper $7 / 01648 D$

Received March 10, 1997 Accepted June 3, 1997 